\title{
Microbiology
}

Chemotherapy

\section{Acinetobacter baumannii Infections in a Tertiary Care Hospital in Mexico over the Past 13 Years}

\author{
R. Morfín-Otero a,b M.D. Alcántar-Curiel ${ }^{c} \quad$ M.J. Rochac ${ }^{c}$ C.M. Alpuche-Arandac \\ J.I. Santos-Preciado ${ }^{c}$ C. Gayosso-Vázquez ${ }^{c} \quad$ J.R. Araiza-Navarrob \\ M. Flores-Vacab S. Esparza-Ahumada ${ }^{a}$ b E. González-Díaz ${ }^{a, b}$ \\ H.R. Pérez-Gómez ${ }^{a, b} \quad$ E. Rodríguez-Noriega ${ }^{a, b}$
}

a Infectious Diseases, Hospital Civil de Guadalajara, Fray Antonio Alcalde, b Instituto de Patología Infecciosa y Experimental, Centro Universitario de Ciencias de la Salud, Universidad de Guadalajara, Guadalajara, and 'Department of Experimental Medicine, School of Medicine, Universidad Nacional Autónoma de México, Mexico City, Mexico

\section{Key Words}

Resistance patterns · Acinetobacter baumannii .

Antimicrobial susceptibility

\begin{abstract}
Background: Acinetobacter baumannii has evolved from an opportunistic pathogen into a common and persistent nosocomial bacterium capable of causing severe infections during endemic and epidemic periods. Methods: The study period extended from January 1999 to December 2011 and involved patients hospitalized at the Hospital Civil de Guadalajara, Fray Antonio Alcalde, Jalisco, Mexico. From each patient, a single isolate was obtained, and a total of 3,680 unique isolates were collected. Susceptibility tests were performed according to the guidelines of the Clinical and Laboratory Standards Institute. Results: A. baumannii has disseminated throughout the Hospital Civil de Guadalajara, Fray Antonio Alcalde, since 1999. A. baumannii isolates obtained from patients treated in the adult intensive care unit represent the majority of the isolates that have been collected. In addition, A. baumannii was isolated from the adult
\end{abstract}

\section{KARGER}

E-Mail karger@karger.com www.karger.com/che neurosurgical ward and the adult internal medicine ward, and these isolates were frequently obtained from secretions. A persistent decrease in the susceptibility of $A$. baumannii isolates to meropenem ( $92 \%$ in 1999 to $12 \%$ in 2011), imipenem and amikacin has been observed. Conclusions: $A$. baumannii became an endemic nosocomial pathogen during the study period at the Hospital Civil de Guadalajara, Fray Antonio Alcalde, and has exhibited a persistent decrease in susceptibility to all categories of antimicrobial agents over the past 13 years.

Copyright $\odot 2013$ S. Karger AG, Basel

\section{Introduction}

Acinetobacter baumannii is a nosocomial pathogen found worldwide that is responsible for a diverse set of serious infections that include bacteremia, ventilatorassociated pneumonia, postsurgical meningitis and skin and skin structure infections [1-3]. Moreover, A. baumannii has evolved from a nosocomial bacterium that primarily affects immunocompromised patients in hos-
(C) 2013 S. Karger AG, Basel

0009-3157/13/0591-0057\$38.00/0
Rayo Morfín-Otero, Instituto de Patología Infecciosa y Experimental Centro Universitario Ciencias de la Salud Universidad de Guadalajara (UdeG), Calle Hospital 308, Col. El Retiro Guadalajara 44280 (Mexico)

E-Mail rayomorfin@gmail.com 
pital intensive care units (ICUs) into a pathogen capable of infecting children, neonates, patients with diabetes mellitus and older adults in community hospitals and nursing homes $[4,5]$. Furthermore, A. baumannii can also spread from adult patients in the ICU to other hospital wards via direct person-to-person (contact) transmission involving an infected patient, a staff member or noninfected patients across a hospital system. As a result, sequential outbreaks, clonal spread, endemicity and dispersal between hospitals and cities can occur [6-8].

The aim of this study is to report the incidence of $A$. baumannii in a tertiary care teaching hospital over the past 13 years, the distribution of A. baumannii within the hospital and selected microbiological and molecular characteristics of the isolates identified.

\section{Methods}

\section{Setting and Study Period}

The study period extended from January 1999 to December 2011 and involved surveillance of $A$. baumannii isolates obtained from patients treated at the Hospital Civil de Guadalajara, Fray Antonio Alcalde, a 1,000-bed, tertiary care teaching hospital. The hospital provides services to the Jalisco state and its capital, Guadalajara, the second largest city in western Mexico, as well as to surrounding states. The hospital consists of adult and pediatric beds distributed among 31 wards in three connected buildings. All of the pediatric units are located in one building, while adult services are distributed between the two other buildings. There is one general adult ICU, two neonatal ICUs and an Obstetrics and Gynecology Service. In 2011, there were 651 patients discharged from the adult ICU, 1,692 patients from the medicine ward, 7,002 from the surgery ward, 2,040 from the neurosurgery ward and 7,398 from the pediatric ward.

\section{Study Design}

The study includes a retrospective review of our hospital clinical microbiology database for all A. baumannii isolates recovered during 13 years. All duplicate A. baumannii isolates were eliminated to ensure that only the first isolate, irrespective of the clinical source, was included in the analysis. All isolates from secondary cases and clusters were also entered in the database. Data regarding hospital areas where A. baumannii was recovered, isolation sites and A. baumannii resistance patterns were recorded. The dataset contained no patient's demographic information. The Centers for Disease Control and Prevention definition for nosocomial infections was used [9]. Whonet 5.6 (World Health Organization, Geneva, Switzerland) software was used for descriptive statistics. Linear trend analysis for seasonal trend over time was performed using SPSS statistical software, version 17.0.

Bacterial Collection and Microbiological Methods

All A. baumannii strains collected between January 1999 and December 2011 were available, and these included 3,680 unique isolates. Originally, a single isolate for each patient was obtained from each culture-positive collection site. Species identification and antibiotic susceptibility for each isolate were analyzed by Sensititre ARIS ${ }^{\circledR}$ 2X (TREK Diagnostic Systems Inc., Westlake, Ohio, USA). The antimicrobial agents tested included amikacin, cefepime, ceftazidime, imipenem and meropenem. Classification of isolates as susceptible or resistant followed Clinical and Laboratory Standards Institute guidelines. Escherichia coli ATCC 25922 and Pseudomonas aeruginosa ATCC 27853 were employed for quality control tests for susceptibility test reagents and methods. A subset of 98 isolates (from 2006-2007) was also analyzed using the commercial assay API $20 \mathrm{NE}$ (Biomeriux ${ }^{\circledR}$ ), in addition to biochemical tests including catalase, oxidase and malonate and growth at 37,40 and $42^{\circ} \mathrm{C}$. All of the strains were identified as belonging to the A. baumannii-calcoaceticus complex. The identification of A. baumannii was confirmed by determining the presence of the $b l a_{\mathrm{OXA}-51}$ gene by PCR [Alcantar-Curiel, unpubl. data, 10].

\section{Analysis of Chromosomal DNA by Pulsed Field Gel}

\section{Electrophoresis}

Genomic DNA was isolated from overnight cultures and prepared as described previously [11]. Briefly, genomic DNA was digested with Apa I (New England Biolabs, Frankfurt, Germany, or Promega, Madison, Wisc., USA), and the resulting restriction digest products were resolved by pulsed field gel electrophoresis (PFGE) using a contoured clamped homogeneous electric field Gene Path system (Bio-Rad). Restriction fragment analysis was interpreted according to criteria suggested by Tenover et al. [12]. Accordingly, a difference of 6 bands or fewer was used to define epidemiological relatedness [11].

\section{Production of Metallo- $\beta$-Lactamases}

Detection by E-Tests. To screen for the presence of metallo- $\beta$ lactamases (MBLs), E-test strips (AB Biodisk, Solna, Sweden) were used according to the manufacturer's instructions. A suspension of each isolate in sterile saline solution was adjusted to the density of a $0.5 \mathrm{McF}$ arland standard, then swabbed onto Müeller-Hinton agar plates in three directions to ensure uniform growth. Once the agar surface was completely dry, an E-test strip containing imipenem and imipenem plus EDTA was applied to each plate with sterile forceps. The plates were subsequently incubated at $35^{\circ} \mathrm{C}$ for $48 \mathrm{~h}$. A reduction in the minimum inhibitory concentration of imipenem by $\geq 3$ twofold dilutions in the presence of EDTA was interpreted as an indicator of MBL production. Equally, the presence of a 'phantom' zone between the two gradient sections or deformation of the imipenem ellipses was also considered indicative of MBL production [13].

Double-Disk Sensitivity Test. Two 10- $\mu$ g imipenem and meropenem disks (Becton Dickinson) were placed on a plate, and appropriate amounts of an EDTA solution were added to one of them to obtain the desired concentration. The inhibition zones of the imipenem/meropenem and imipenem/meropenem-EDTA disks were compared after $16-18 \mathrm{~h}$ of incubation in air at $35^{\circ} \mathrm{C}$. The inhibition zone diameter for MBL-positive Acinetobacter spp. increased by $6-13 \mathrm{~mm}$, while that for MBL-negative isolates increased by $1-7 \mathrm{~mm}[14]$.
58

Chemotherapy 2013;59:57-65

DOI: $10.1159 / 000351098$
Morfín-Otero et al. 
Table 1. Distribution of A. baumannii isolates by hospital ward

\begin{tabular}{|c|c|c|c|c|c|c|c|c|c|c|c|c|}
\hline Ward & \multicolumn{12}{|l|}{ Year } \\
\hline ICU & 20 & 31.1 & 29.3 & 25.3 & 20.4 & 22.9 & 24.6 & 30.6 & 36.2 & 34 & 28.4 & 22.4 \\
\hline Medicine & 23.8 & 31.1 & 16.9 & 21.6 & 23.1 & 16.8 & 19 & 27.4 & 21.3 & 28.2 & 28.3 & 26.4 \\
\hline Surgery & 7.6 & 2.8 & 23.3 & 27.7 & 23.1 & 22.5 & 26.3 & 12.6 & 23.5 & 17.9 & 13.9 & 18.8 \\
\hline
\end{tabular}

Results are shown as percentages. In 1999, a total of 18 isolates were found, with the following distribution: Surgery, 6; Pediatric, 5; Medicine, 4; Neurosurgery, 2; ICU, 1.

Table 2. Distribution of A. baumannii isolates by isolation site

\begin{tabular}{|c|c|c|c|c|c|c|c|c|c|c|c|c|}
\hline \multirow[t]{2}{*}{ Isolation site } & \multicolumn{12}{|l|}{ Year } \\
\hline & $\begin{array}{l}2000 \\
(\mathrm{n}=105)\end{array}$ & $\begin{array}{l}2001 \\
(\mathrm{n}=106)\end{array}$ & $\begin{array}{l}2002 \\
(\mathrm{n}=201)\end{array}$ & $\begin{array}{l}2003 \\
(n=166)\end{array}$ & $\begin{array}{l}2004 \\
(\mathrm{n}=147)\end{array}$ & $\begin{array}{l}2005 \\
(\mathrm{n}=244)\end{array}$ & $\begin{array}{l}2006 \\
(\mathrm{n}=288)\end{array}$ & $\begin{array}{l}2007 \\
(\mathrm{n}=411)\end{array}$ & $\begin{array}{l}2008 \\
(\mathrm{n}=472)\end{array}$ & $\begin{array}{l}2009 \\
(\mathrm{n}=379)\end{array}$ & $\begin{array}{l}2010 \\
(\mathrm{n}=537)\end{array}$ & $\begin{array}{l}2011 \\
(n=606)\end{array}$ \\
\hline Secretions & 59 & 53.7 & 49.7 & 59.6 & 52.3 & 52.4 & 54.5 & 56.6 & 52.7 & 51.1 & 50.4 & 38.9 \\
\hline Vascular catheter & 12.3 & 15 & 13.4 & 13.2 & 14.9 & 15.5 & 13.1 & 10.7 & 15.4 & 13.9 & 16.7 & 12 \\
\hline Blood & 4.7 & 15 & 16.4 & 9 & 10.2 & 7.7 & 6.5 & 8.5 & 9.7 & 10.5 & 7.6 & 8.5 \\
\hline Respiratory sources & 13.3 & 4.7 & 6.4 & 7.2 & 9.5 & 11 & 18.7 & 17.2 & 15 & 13.9 & 11.7 & 30.5 \\
\hline Urine & 7.6 & 4.7 & 8.4 & 6.6 & 7.4 & 7.3 & 2.4 & 4.8 & 4 & 5.8 & 9.4 & 6.9 \\
\hline Cerebral spinal fluid & 0 & 6.6 & 3.4 & 2.4 & 4.7 & 1.2 & 2.7 & 0.4 & 2.3 & 1.8 & 3.1 & 1.8 \\
\hline Pleural fluid & 2.8 & 0 & 1.9 & 1.8 & 0.6 & 4.5 & 1.7 & 1.4 & 0.6 & 2.6 & 0.7 & 1.1 \\
\hline
\end{tabular}

Results are shown as percentages. Respiratory sources include tracheal and bronchial specimens. In 1999, a total of 18 isolates were found, with the following distribution: secretions, 9; respiratory sources, 3; blood, 3; urine, 3.

\section{Results}

\section{Evolution of A. baumannii}

The first $A$. baumannii isolate detected at the Hospital Civil de Guadalajara (Jalisco, Mexico) was obtained from a patient treated in the adult ICU. From this ward, A. baumannii was found to spread to the adult medicine ward and the neurosurgical ward, then to the rest of the hospital. In 1999, there were $18 \mathrm{~A}$. baumannii isolates identified, then between 2000 and 2001, this number increased to $>100$. In 2010, $>500 \mathrm{~A}$. baumannii isolates were collected. The adult ICU had the highest percentage of isolates in the years 2001, 2002, 2005 and 2007-2010. The second highest percentage of isolates was detected in the surgical ward in the years 2003, 2004 and 2006 (table 1). Between 2000 and 2001, A. baumannii isolates were frequently found in the adult neurosurgical service. More- over, during the last 10 years of observation, this ward was the fourth most common hospital area for A. baumannii isolation (table 1). In contrast, the percentage of $A$. baumannii isolates obtained from the pediatric ward remained stable (e.g. $<15 \%$ ) throughout the observation period (table 1). In 2011, the prevalence of A. baumannii isolates was $20.8 \%$ for the ICU, $9.4 \%$ for the medicine ward, $1.6 \%$ for the surgery ward, $5.8 \%$ for the neurosurgery ward and $1 \%$ for the pediatric ward.

\section{A. baumannii Isolation Sources, Ranking and \\ Seasonal Distribution}

Since 2000, A. baumannii has frequently been isolated from secretions, with this site accounting for $>50 \%$ of all isolation sites monitored through 2011 (table 2). Isolation of $A$. baumannii from vascular catheters was the second most common site, but was surpassed by isolates from 
Fig. 1. Seasonal distribution of A. baumannii. Linear trend analysis was not significant.

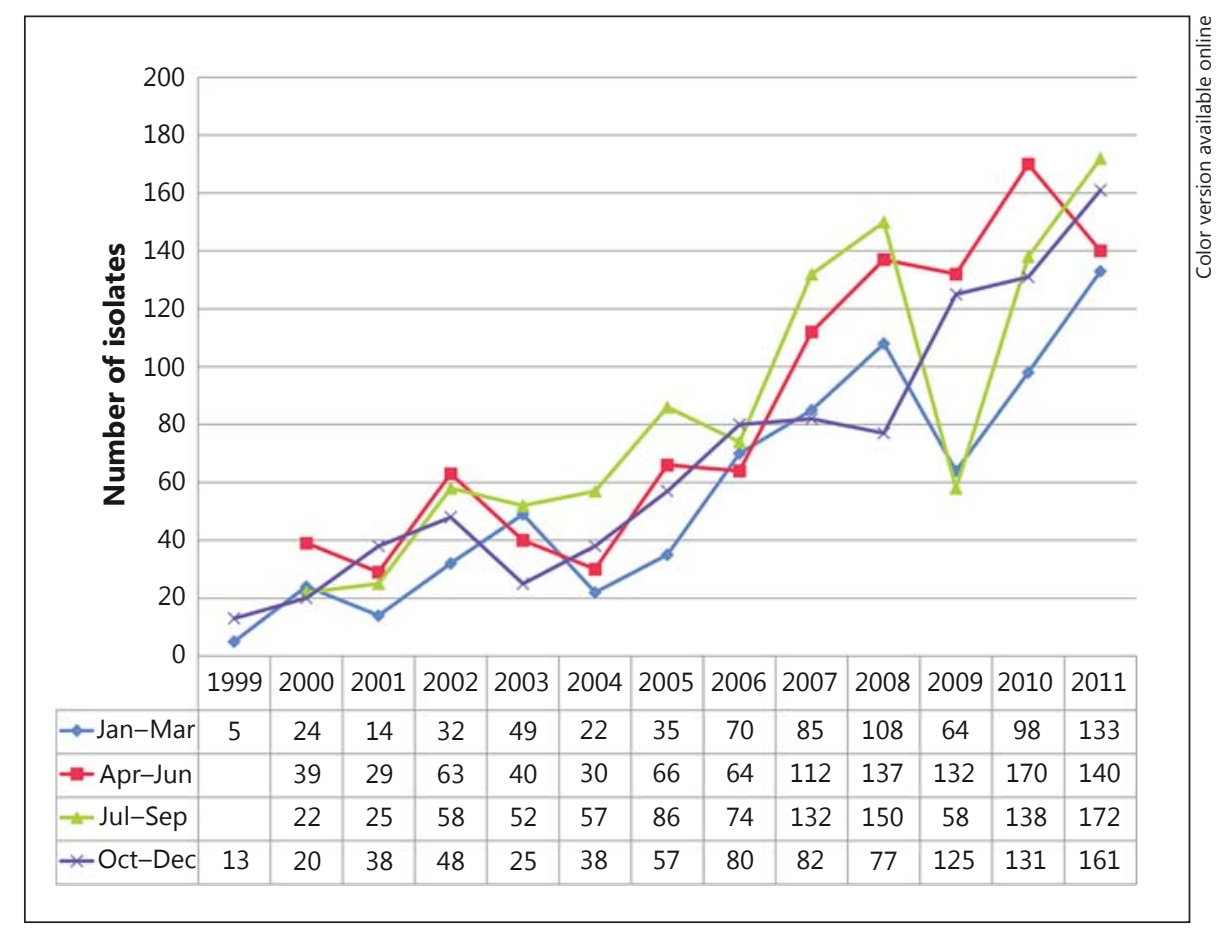

Table 3. The 5 most frequently isolated bacterial pathogens over time

\begin{tabular}{|c|c|c|c|c|}
\hline \multirow{2}{*}{$\begin{array}{l}\text { Isolation } \\
\text { rank }\end{array}$} & \multicolumn{4}{|l|}{ Year } \\
\hline & 2002 & 2005 & 2008 & 2011 \\
\hline 1 & Escherichia coli & Escherichia coli & Escherichia coli & Escherichia coli \\
\hline 2 & Staphylococcus epidermidis & Staphylococcus aureus & Staphylococcus aureus & Acinetobacter baumannii \\
\hline 3 & Staphylococcus aureus & Staphylococcus epidermidis & Staphylococcus epidermidis & Staphylococcus aureus \\
\hline 4 & Klebsiella pneumoniae & Pseudomonas aeruginosa & Pseudomonas aeruginosa & Pseudomonas aeruginosa \\
\hline 5 & Pseudomonas aeruginosa & Klebsiella pneumoniae & Acinetobacter baumannii & Staphylococcus epidermidis \\
\hline
\end{tabular}

respiratory sources in 2000, 2006, 2007 and 2011 (table 2). The fourth and fifth most common isolation sites were blood and urine, respectively, with a small number of isolates obtained from cerebral spinal fluid and pleural fluid (table 2). In 2007, A. baumannii became, for the first time, 1 of the 5 most frequent bacterial pathogens isolated. In 2009 , it was the fourth most frequent bacterial pathogen, displacing other nosocomial pathogens such as P. aeruginos $a$ and becoming the second most common Gram-negative pathogen after E. coli in 2011 (table 3). In addition, $A$. baumannii was more frequently isolated during the dry, hot months between April and June and during the hot, rainy season between July and September, although this trend was not statistically significant (fig. 1).

60
PFGE Analysis and Susceptibility of A. baumannii Isolates to Selected Antibiotics

Thirteen types of $A$. baumannii clones were identified from the PFGE patterns observed. Multiple A. baumannii clones were present in some samples, and clones L and D were predominant among the ICU isolates. Clones L and D were also found to be the cause of nosocomial outbreaks (fig. 2). During the study period, a persistent decrease in the susceptibility of $A$. baumannii isolates to meropenem, imipenem and amikacin was observed (table 4). During 2006-2007, there was an increase in the percentage of isolates susceptible to cefepime, imipenem and meropenem, probably related to predominant clones with different sensitivities. However, a subset of A. baumannii clones were susceptible to amikacin, imipenem and me- 
Fig. 2. Dendogram obtained by PFGE analysis. PFGE was run in 65 selected isolates, and 12 clones were detected (A-L). Representative patterns of the 12 clones are shown.

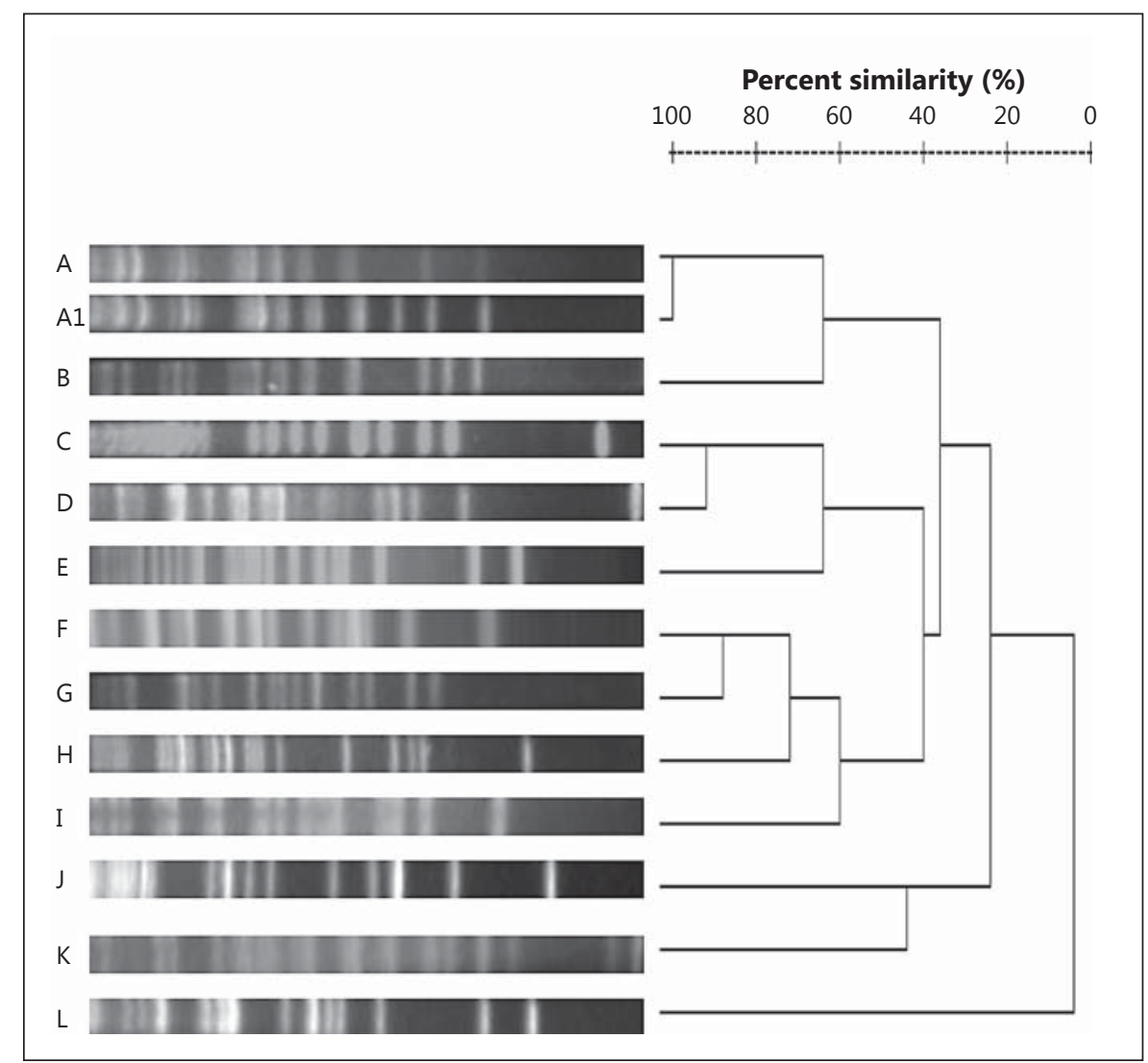

Table 4. Susceptibility of A. baumannii to selected antibiotics

\begin{tabular}{|c|c|c|c|c|c|c|c|c|c|c|c|c|c|}
\hline Antibiotic & $\begin{array}{l}1999 \\
(\mathrm{n}=18)\end{array}$ & $\begin{array}{l}2000 \\
(\mathrm{n}=105)\end{array}$ & $\begin{array}{l}2001 \\
(\mathrm{n}=106)\end{array}$ & $\begin{array}{l}2002 \\
(\mathrm{n}=201)\end{array}$ & $\begin{array}{l}2003 \\
(\mathrm{n}=166)\end{array}$ & $\begin{array}{l}2004 \\
(\mathrm{n}=147)\end{array}$ & $\begin{array}{l}2005 \\
(\mathrm{n}=244)\end{array}$ & $\begin{array}{l}2006 \\
(\mathrm{n}=288)\end{array}$ & $\begin{array}{l}2007 \\
(\mathrm{n}=411)\end{array}$ & $\begin{array}{l}2008 \\
(\mathrm{n}=472)\end{array}$ & $\begin{array}{l}2009 \\
(\mathrm{n}=379)\end{array}$ & $\begin{array}{l}2010 \\
(\mathrm{n}=537)\end{array}$ & $\begin{array}{l}2011 \\
(n=606)\end{array}$ \\
\hline Amikacin & 33.3 & 31.7 & 39.6 & 22.4 & 29.6 & 25.9 & 23 & 21.5 & 19 & 41.5 & 35.9 & 15.5 & 20.8 \\
\hline Cefepime & 45.5 & 51.6 & 64.2 & 66.2 & 70.7 & 68 & 47.9 & 72 & 74.6 & 46.3 & 38 & 35 & 26.2 \\
\hline Ceftazidime & 11.1 & 21.2 & 18.3 & 11.4 & 15.1 & 25.9 & 16.5 & 21.8 & 26.3 & 15.9 & 13.5 & 5.6 & 8.6 \\
\hline Meropenem & 91.7 & 63.2 & 80.2 & 73.5 & 74.1 & 80 & 58.5 & 70.5 & 60.4 & 41.2 & 19.8 & 9.9 & 11.8 \\
\hline
\end{tabular}

Results are shown as percentages.

ropenem. The most predominant clone, $\mathrm{L}$, was characterized to be $47 \%$ resistant and $53 \%$ intermediate to meropenem, and to be $71 \%$ susceptible and $29 \%$ intermediate to imipenem. In contrast, the second most frequent clone type, clone D, was $100 \%$ resistant to meropenem and $91 \%$ resistant to imipenem (table 5).

Acinetobacter baumannii at a Medical Center in Mexico
MBL producers were also screened using the doubledisk diffusion method with meropenem and EDTA. Analysis of a subset of 98 isolates revealed that $48 \%$ (47 out of 98) were resistant to either meropenem or imipenem or both. Of these, $83 \%$ (39 out of 47 ) were positive for MBLs on 1 of the 2 assays. The remaining 17\% were 
Table 5. Susceptibility patterns in representative A. baumannii clones

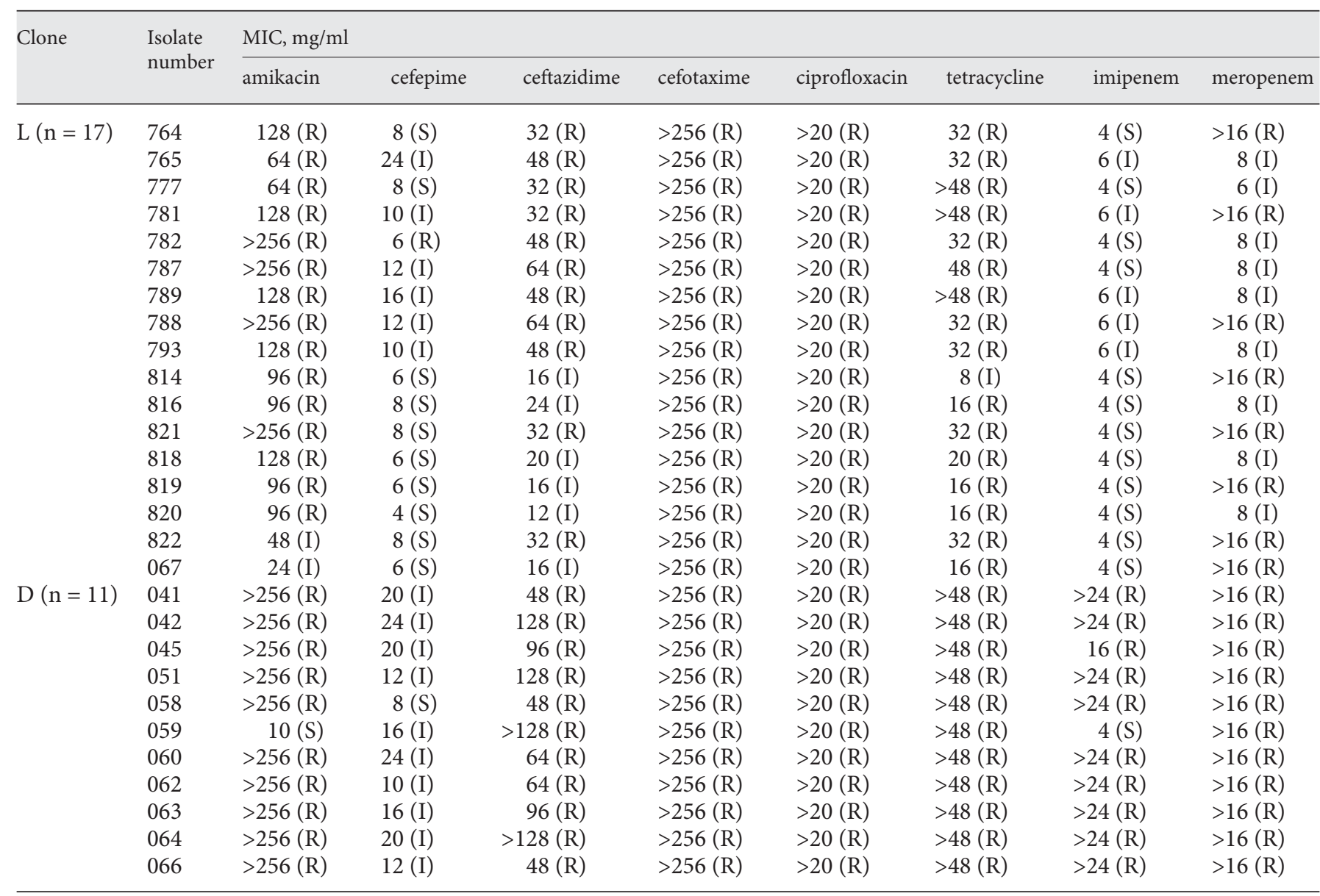

MIC = Minimum inhibitory concentration; $\mathrm{R}=$ resistant; $\mathrm{S}=$ susceptible; $\mathrm{I}$ = intermediate.

negative, suggesting another mechanism of resistance such as mutation of porins or efflux pumps. Correspondingly, these isolates appear to produce MBLs. This was corroborated by the detection of carbapenemase genes by PCR [Alcantar-Curiel, unpubl. data].

\section{Discussion}

Currently, A. baumannii is considered to be one of the most difficult bacterial species to contain and treat in a hospital setting. Accordingly, it is critical to be able to document and understand the ability, dissemination pathways and resistance patterns of A. baumannii clones. Therefore, we report our 13-year experience with identifying A. baumannii isolates at our hospital.
The sustained, endemic nature of A. baumannii described in the present report illustrates what is now recognized as an important characteristic of A. baumannii. That is, once A. baumannii is introduced into a hospital, it may persist and become endemic $[15,16]$. After disseminating throughout our hospital system from the adult ICU, A. baumannii became 1 of the 5 most frequent bacterial pathogens isolated in 2007. Furthermore, between 2009 and 2011, it was the fourth most frequent bacterial pathogen detected, displacing other nosocomial pathogens, including $P$. aeruginosa, and becoming the second most common Gram-negative pathogen only after $E$. coli. While there are several possible causes for the dissemination of $A$. baumannii that were observed, we hypothesize that the most likely explanation involves patients who were admitted to the ICU for stabilization after a surgical procedure and required mechanical ventila- 
tion. While in the ICU, these patients acquired $A$. baumannii, which was then transferred to other areas as patients were moved to the neurosurgical ward or the adult internal medicine ward. As such, this situation would have facilitated the dissemination of A. baumannii in our hospital [17]. Patients in ICU are usually sicker, have more invasive procedures, receive prolonged antibiotic therapy and are in close contact with similar patients. The combination of all these factors compromises the immune system of a patient, facilitating initial colonization and subsequent progression to severe infection. A. baumannii colonizes the respiratory tract, where it can advance to nosocomial pneumonia $[18,19]$. In addition, the endemicity and nosocomial outbreak of multidrug-resistant A. baumannii at our hospital is predominantly related to the coexistence of multiple clones and the spread of 2 carbapenem-resistant clones. Similar to other reports, it was found that during the epidemic periods, 2 epidemic A. baumannii clones coexisted with other related A. baumannii strains $[15,20]$.

Throughout the study period, the adult ICU was found to be an environment where the risk of A. baumannii transmission between colonized or infected patients was higher than other clinical areas [21]. Moreover, A. baumannii was found to be a nosocomial pathogen frequently isolated from all types of secretions at our hospital, including those from the respiratory tract [22]. Accordingly, medical personnel in these departments have been advised to be aware of any patient with an abnormal secretion. Once identified, these patients are to be considered potential carriers of A. baumannii, and contact precautions are strictly enforced.

A. baumannii was more frequently isolated during the summer months at our hospital. Although the correlation between season and frequency was not statistically significant, given that this phenomenon has also been observed in other areas of the world that have similar temperature increases during the summer months, we consider that this pattern should be further investigated [23].

In an attempt to control the spread of $A$. baumannii in our hospital, we have moved A. baumannii-positive patients to an adult infectious diseases ward. In addition, during outbreaks of A. baumannii detected in the Neurosurgical Unit, all patients were moved to this infectious diseases ward. During these periods, no dispersal occurred within the ward. During periods of peak admission to the ICU, patients at risk also had their length of stay shortened and were subsequently moved to the infectious diseases ward. A similar process has been implemented at other hospitals $[24,25]$.

Acinetobacter baumannii at a Medical Center in Mexico
During the period studied, some A. baumannii clones were found to become increasingly resistant to carbapenems. For example, some A. baumannii isolates developed the ability to produce MBLs, including blaVIM-4, blaIMP-1 and the carbapenemase blaOXA-24 [26]. The persistent decrease in susceptibility to imipenem is also occurring in other Latin America countries [27]. A recent report regarding the evolution of antimicrobial resistance among Gram-negative bacilli in Latin America documented that imipenem-resistant Acinetobacter spp. rates increased from $6.4,12.6$ and $0.0 \%$ in the $1997-1999$ period to 84.9, 71.4 and $50.0 \%$ in 2008-2010 in Argentina, Brazil and Chile, respectively. Further, oxacillinase (OXA)-producing Acinetobacter spp. were documented in Argentina (OXA-23 and -24), Brazil (OXA-23), Chile (OXA-58) and Mexico (OXA-24) [27].

A delay in the administration of tigecycline or colistin, alone or in combination, has the potential to increase the risk of mortality [28]. In late 2010, colistin was introduced in Mexico. Correspondingly, when an A. baumannii infection was encountered outside of the ICU, which has frequently occurred in recent years, the majority of patients are started on an empirical regimen that includes tigecycline or colistin. Furthermore, these two drugs have been reported to be administered for the treatment of severe A. baumannii infections [29, 30]. For example, administration of tigecycline in conjunction with an aggressive infection control strategy has been employed successfully to control ICU outbreaks. However, A. baumannii can develop resistance to both colistin and tigecycline, and thus, extreme vigilance is required to diagnose the development of resistance during treatment [31].

Although our study includes a significant span of time and number of isolates, it has several limitations. The findings from our tertiary care teaching hospital may not be pertinent to other hospitals. In terms of the samples analyzed, no environmental or healthcare worker cultures were included in the study, and no matched cohort or control cases were involved. In relation to the data, patient data did not include the severity of present illness or the patient comorbidities, both of which could provide important context for infection, nor did it distinguish between colonization or infection so it was impossible to discern the progression of colonization to infection. The semiautomated identification system used cannot differentiate all of the members of the A. calcoaceticus-A. baumannii complex and cannot properly break down other Acinetobacter species, i.e. Acinetobacter genomic species 3 and Acinetobacter genomic species 13TU. Further, the sensitivity panels used did not include tigecycline or co-

Chemotherapy 2013;59:57-65 
listin, preventing us from evaluating the evolution of susceptibility of $A$. baumannii to those antibiotics. The detection of MBL production using E-test strips can produce false negative results. Finally, only some of the mechanisms involved in $A$. baumannii resistance were investigated in selected isolates, with some chosen $A$. baumannii isolates shown to have MBL genes including the $b l a_{\mathrm{OXA}-51}$ gene.

In conclusion, the epidemiology of $A$. baumannii in a tertiary care teaching hospital in Mexico over the past 13 years is described. In this hospital, A. baumannii has become an endemic nosocomial pathogen that has not been eradicated from its main reservoir. Currently, the transfer of infected patients to an infectious diseases ward and the early treatment of $A$. baumannii-infected patients have shown limited success at our institution. It is anticipated that adequate antimicrobial stewardship and improved control and prevention measures will further help decrease the spread and impact of A. baumannii at our hospital.

\section{References}

-1 Perez F, Hujer AM, Hujer KM, Decker BK, Rather PN, Bonomo RA: Global challenge of multidrug-resistant Acinetobacter baumannii. Antimicrob Agents Chemother 2007;51: 3471-3484.

-2 Peleg AY, Seifert H, Paterson DL: Acinetobacter baumannii: emergence of a successful pathogen. Clin Microbiol Rev 2008;21:538582.

3 Munoz-Price LS, Weinstein RA: Acinetobacter infection. N Engl J Med 2008;358: 1271-1281.

$\checkmark 4$ de Benedictis FM, Osimani P, Gabriele C: Acinetobacter baumannii infections in children. Lancet Infect Dis 2010;10:143-144.

$\checkmark 5$ Sengstock DM, Thyagarajan R, Apalara J, Mira A, Chopra T, Kaye KS: Multidrug-resistant Acinetobacter baumannii: an emerging pathogen among older adults in community hospitals and nursing homes. Clin Infect Dis 2010;50:1611-1616.

6 Shelburne SA 3rd, Singh KV, White AC Jr, Byrne L, Carmer A, Austin C, Graviss E, Stager C, Murray BE, Atmar RL: Sequential outbreaks of infections by distinct Acinetobacter baumannii strains in a public teaching hospital in Houston, Texas. J Clin Microbiol 2008 46:198-205.

7 Runnegar N, Sidjabat H, Goh HM, Nimmo GR, Schembri MA, Paterson DL: Molecular epidemiology of multidrug-resistant Acinetobacter baumannii in a single institution over a 10-year period. J Clin Microbiol 2010; 48:4051-4056.

-8 van den Broek PJ, van der Reijden TJ, van Strijen E, Helmig-Schurter AV, Bernards AT, Dijkshoorn L: Endemic and epidemic Acinetobacter species in a university hospital: an 8-year survey. J Clin Microbiol 2009;47:35933599.

$>9$ Garner JS, Jarvis WR, Emori TG, Horan TC, Hughes JM: CDC definitions for nosocomial infections, 1988. Am J Infect Control 1988;16: $128-140$.
10 Hamouda A, Evans BA, Towner KJ, Amyes SG: Characterization of epidemiologically unrelated Acinetobacter baumannii isolates from four continents by use of multilocus sequence typing, pulsed-field gel electrophoresis, and sequence-based typing of bla(OXA51-like) genes. J Clin Microbiol 2010;48: 2476-2483.

11 Seifert H, Dolzani L, Bressan R, van der Reijden T, van Strijen B, Stefanik D, Heersma H, Dijkshoorn L: Standardization and interlaboratory reproducibility assessment of pulsed-field gel electrophoresis-generated fingerprints of Acinetobacter baumannii. J Clin Microbiol 2005;43:4328-4335.

12 Tenover FC, Arbeit RD, Goering RV, Mickelsen PA, Murray BE, Persing DH, Swaminathan B: Interpreting chromosomal DNA restriction patterns produced by pulsed-field gel electrophoresis: criteria for bacterial strain typing. J Clin Microbiol 1995;33:2233-2239.

13 Walsh TR, Bolmstrom A, Qwarnstrom A, Gales A: Evaluation of a new Etest for detecting metallo-beta-lactamases in routine clinical testing. J Clin Microbiol 2002;40:27552759.

14 Yong D, Lee K, Yum JH, Shin HB, Rossolini GM, Chong Y: Imipenem-EDTA disk method for differentiation of metallo-beta-lactamase-producing clinical isolates of Pseudomonas spp. and Acinetobacter spp. J Clin Microbiol 2002;40:3798-3801.

15 Weisenberg SA, Schuetz AN, Alexander EA, Eiss B, Behta M, Saiman L, Larone DH, Jenkins SG, Rhee KY: Endemic Acinetobacter baumannii in a New York hospital. PLoS One 2011;6:e28566.

16 Manikal VM, Landman D, Saurina G, Oydna E, Lal H, Quale J: Endemic carbapenem-resistant Acinetobacter species in Brooklyn, New York: citywide prevalence, interinstitutional spread, and relation to antibiotic usage. Clin Infect Dis 2000;31:101-106

17 D'Agata EM, Thayer V, Schaffner W: An outbreak of Acinetobacter baumannii: the importance of cross-transmission. Infect Control Hosp Epidemiol 2000;21:588-591.
18 Ledizet M, Murray TS, Puttagunta S, Slade MD, Quagliarello VJ, Kazmierczak BI: The ability of virulence factor expression by Pseudomonas aeruginosa to predict clinical disease in hospitalized patients. PLoS One 2012; 7:e49578.

19 Tilley PA, Roberts FJ: Bacteremia with Acinetobacter species: risk factors and prognosis in different clinical settings. Clin Infect Dis1994;18:896-900.

20 Maslow JN, Glaze T, Adams P, Lataillade M: Concurrent outbreak of multidrug-resistant and susceptible subclones of Acinetobacter baumannii affecting different wards of a single hospital. Infect Control Hospital Epidemiol 2005;26:69-75.

21 Lee SO, Kim NJ, Choi SH, Hyong Kim T, Chung JW, Woo JH, Ryu J, Kim YS: Risk factors for acquisition of imipenem-resistant Acinetobacter baumannii: a case-control study. Antimicrob Agents Chemother 2004; 48:224-228.

22 Garza-Gonzalez E, Llaca-Diaz JM, BosquesPadilla FJ, Gonzalez GM: Prevalence of multidrug-resistant bacteria at a tertiary-care teaching hospital in Mexico: special focus on Acinetobacter baumannii. Chemotherapy 2010;56:275-279.

23 Fukuta Y, Clarke LG, Shields RK, Wagener MM, Pasculle AW, Doi Y: Lack of seasonality in the occurrence of multidrug-resistant Acinectobacter baumannii complex. Infect Control Hosp Epidemiol 2012;33:1051-1052.

24 Fournier PE, Richet H: The epidemiology and control of Acinetobacter baumannii in health care facilities. Clin Infect Dis 2006;42:692699.

25 Apisarnthanarak A, Warren DK, Fraser VJ: Creating a cohort area to limit transmission of pandrug-resistant Acinetobacter baumannii in a Thai tertiary care center. Clin Infect Dis 2009;48:1487-1488. 
26 Gonzalez-Chavez MI, Morfin-Otero R, Jarillo-Quijada C, Gayosso-Vazquez E, Rodriguez-Noriega E, Santos-Preciado JI, GionoCerezo S, Alpuche-Aranda CM, Alcantar-Curiel MD: First report of blavim-4, blaimp-1 and blaoxa-24-producing Acinetobacter baumannii clones isolated from nosocomial infections in Mexico (abstract C2-648). Abstracts of the 51st Interscience Conference on Antimicrobial Agents and Chemotherapy, Chicago, Ill., September 2011.

27 Gales AC, Castanheira M, Jones RN, Sader HS: Antimicrobial resistance among Gramnegative bacilli isolated from Latin America: results from SENTRY Antimicrobial Surveillance Program (Latin America, 2008-2010). Diagn Microbiol Infect Dis 2012;73:354-360.

28 Esterly JS, Griffith M, Qi C, Malczynski M, Postelnick MJ, Scheetz MH: Impact of carbapenem resistance and receipt of active antimicrobial therapy on clinical outcomes of Acinetobacter baumannii bloodstream infections. Antimicrob Agents Chemother 2011; 55:4844-4849.

29 Garnacho-Montero J, Ortiz-Leyba C, Jimenez-Jimenez FJ, Barrero-Almodovar AE, Garcia-Garmendia JL, Bernabeu-Wittel IM, Gallego-Lara SL, Madrazo-Osuna J: Treat- ment of multidrug-resistant Acinetobacter baumannii ventilator-associated pneumonia (VAP) with intravenous colistin: a comparison with imipenem-susceptible VAP. Clin Infect Dis 2003;36:1111-1118.

30 Anthony KB, Fishman NO, Linkin DR, Gasink LB, Edelstein PH, Lautenbach E: Clinical and microbiological outcomes of serious infections with multidrug-resistant gram-negative organisms treated with tigecycline. Clin Infect Dis 2008;46:567-570.

31 Fishbain J, Peleg AY: Treatment of Acinetobacter infections. Clin Infect Dis 2010;51:7984.

\section{Erratum}

In the article by Matsunaga et al., entitled 'The polyketide synthase-associated multidrug tolerance in Mycobacterium intracellulare clinical isolates' [Chemotherapy 2012;58:341348, DOI: $10.1159 / 000343311$ ], the second author's name is misspelled and should read Shinji Maeda. 